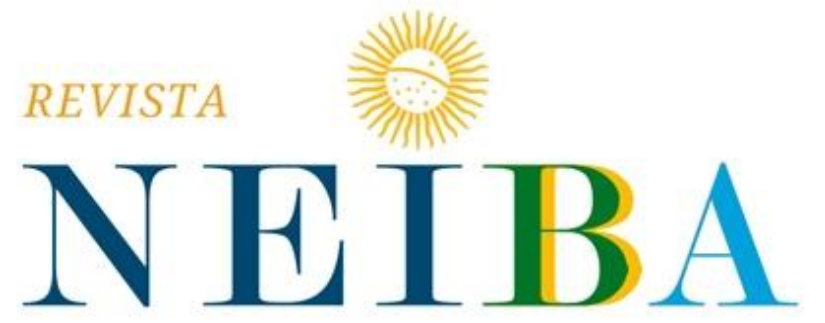

CADERNOS ARGENTINA-BRASIL
Volume 8, 2019, p. 01-22

DOI: 10.12957/neiba.2019.40101 | e40101 | ISSN: 2317-3459

\title{
DO PRINCÍPIO À PRÁTICA: UM ESTUDO SOBRE AS POLÍTICAS PÚBLICAS PARA DIREITOS HUMANOS E O CASO DO REFÚGIO NO CANADÁ
}

FROM PRINCIPLE TO PRACTICE: A STUDY ON PUBLIC POLICIES FOR HUMAN RIGHTS AND THE CASE OF REFUGE IN CANADA

\section{Gustavo do Amaral Loureiro ${ }^{1}$}

\section{Luiz Felipy dos Santos Costa Leomil ${ }^{2}$}

${ }^{1}$ Universidade Federal do Estado do Rio de Janeiro (Unirio), Rio de Janeiro, RJ, Brasil. Email: gus.amaral7@gmail.com ORCID: 0000-0002-7429-7172

${ }^{2}$ Carleton University, Toronto, Ontario, Canadá. E-mail: luizleomil@icloud.com ORCID: 0000-0002-5456-1378

Recebido em: 11 fev. 2019 | Aceito em: 03 dez. 2019. 
Os Direitos Humanos são princípios que orientam ou devem orientar as ações dos Estados, sociedades e indivíduos, porém, estes não possuem necessariamente o poder de configurar obrigações jurídicas. Bucci (2001) argumenta que para transformá-los de princípios em instrumentos com poder de regra, é necessário estabelecer políticas públicas para direitos humanos. Assim, este trabalho busca verificar a hipótese da autora através de um estudo de caso sobre o sistema de refúgio no Canadá a fim de observar os efeitos causados pela construção de uma política pública apropriada para abordar o problema em questão. O país, que aderiu tardiamente aos acordos internacionais sobre o refúgio, não somente adequou-se às normas propostas pela comunidade internacional, como tornou-se referência na recepção, proteção e reassentamento de refugiados.

Palavras-chave: Políticas Públicas, Direitos Humanos, Canadá.

\section{ABSTRACT}

Human Rights are principles that guide, or should guide, the actions of States and societies and individuals, but they don't necessarily have the power to create judicial obligations. Bucci (2001) states that the path to transform them from principles to tools with legal power, it is necessary to develop public policies for human rights. Therefore, this work aspires to verify the author's hypothesis through a case study on Canada's refuge system to observe the effects of the development of an appropriate public policy to this end. The country, a late adherent to the international treaties on refugees, not only adapted to the norms proposed by the international community but also became a point of reference for the reception, protection and resettlement of refugees.

Keywords: Public Policies, Human Rights, Canada.

\section{INTRODUÇÃO}

Cançado Trindade (2003) aponta que, na contemporaneidade, há uma grande preocupação por parte da comunidade internacional em construir um sistema de proteção legal que seja capaz de proteger a dignidade humana. O Direito Internacional dos Direitos Humanos é a cristalização de tais anseios, um conjunto de normas e princípios cujo objetivo central é combater as percepções de injustiça causadas pelas 
disparidades entre sociedades e indivíduos que, caso contrário, seriam perpetuadas (Bielefeldt, 2006).

Segundo Bucci (2001, p. 5), à medida que se buscam maneiras de transformar os direitos humanos de simples princípios em instrumentos concretos, capazes de garantir a proteção da dignidade humana, a construção de políticas públicas apropriadas é apresentada como solução viável. Mas o que, de fato, constituiria uma política pública?

A definição clássica de política pública, segundo Dye (2013, p. 3), é "qualquer coisa que governos escolham fazer ou não fazer"1, as políticas públicas podem "regular comportamentos, organizar burocracias, distribuir benefícios ou extrair impostos - ou todas estas coisas de uma vez" ${ }^{2}$. Apesar disso, o conceito adotado por Dye é visto por alguns autores do campo como muito ampla, pois a ausência de uma política, apesar de, em alguns casos, intencional, nem sempre constituirá uma posição formal ou orientação governamental. Ou seja, a inação estatal, apesar de, em alguns casos, poder ser política pública, nem sempre o será.

Ainda, parte da literatura de políticas públicas, trará o debate sobre a origem destas políticas - seriam elas exclusivamente construídas pelos governos ou outros atores seriam capazes de desenhá-la? Duas visões principais são destacadas por Secchi (2014), a visão estatista, que defende que o Estado possui o monopólio sobre a produção de políticas públicas, e a corrente multicêntrica, que acredita que tais políticas podem surgir de outros atores, como a iniciativa privada, organizações nãogovernamentais e organismos multilaterais. Para efeitos práticos, este trabalho adotará a primeira perspectiva, porém, sem descartar a importância que outros atores nãogovernamentais podem possuir na implementação de novas políticas, já que, segundo Theodolou (1995), política pública, idealmente, além de envolver todos os níveis de governo, não é necessariamente restrita aos atores formais, atores informais também são extremamente importantes nos processos de construção e consolidação de uma política.

Secchi (2014) afirma que uma política pública deve ser compreendida como uma diretriz proposta pelos atores governamentais, os protagonistas na formulação destas políticas, que pode ou não ser implementada. A função de uma política pública é, idealmente, a resolução de um problema público. Para o autor (p. 44), "um problema público é a diferença entre o que é e aquilo que se gostaria que fosse a realidade pública". Um problema público pode surgir repentinamente, como um acidente ambiental ou uma catástrofe natural, ou pode já estar presente há certo tempo,

\footnotetext{
1 Do original, em língua inglesa: "whatever governments choose to do or not to do."

2 Do original, em língua inglesa: "regulate behavior, organize bureaucracies, distribute benefits, or extract taxes - or all of these things at once."
} 
tardando a tornar-se foco da atenção da coletividade, fazendo-o apenas de maneira gradativa.

Apesar de consistirem em decisões autorizadas ou sancionadas por atores governamentais, as políticas públicas contam com a colaboração de atores informais e da sociedade para sua execução adequada. Ou seja, apesar de serem o resultado de processos iniciados em instâncias governamentais, elas interagem com diversos elementos integrantes da sociedade como um todo, incluindo organizações, coletividades e indivíduos (Salisbury, 1995; Secchi, 2014). A influência destes atores externos ao âmbito governamental deve ser calculada e projetada para garantir o sucesso de uma nova política pois os atores governamentais não existem em um vácuo, desconectados dos demais.

Pode-se, então, resumir política pública como o campo do conhecimento que
busca, ao mesmo tempo, "colocar o governo em ação" e/ou analisar essa
ação (variável independente) e, quando necessário, propor mudanças no
rumo ou curso dessas ações (variável dependente). A formulação de políticas
públicas constitui-se no estágio em que os governos democráticos traduzem
seus propósitos e plataformas eleitorais em programas e ações que
produzirão resultados ou mudanças no mundo real (Souza 2006, p. 26).

A teoria do neoinstitucionalismo traz para o estudo das políticas públicas uma grande contribuição sobre os processos anteriores e posteriores à formulação e implementação de uma nova política. Rocha (2005) afirma que a "política pública, seja qual for, envolve, cria, mantém e muda instituições" (p. 5), representando um conjunto de regras e procedimentos que alteram a vida política, moldando comportamentos de atores e organizações, além de inserir gradualmente novos valores orientadores e novas práticas. O Estado, através de suas ações implementadas através de sua burocracia, ou seus funcionários, buscam "reproduzir o controle de suas instituições sobre a sociedade, reforçando sua autoridade, seu poder político e sua capacidade de ação e controle sobre o ambiente que o circunda" (Rocha 2005, p. 14). Diferente das correntes dominantes durante meados do século XX, como o pluralismo e o marxismo, os neoinstitucionalistas defendem que o Estado não se submete simplesmente a grupos ou interesses localizados na sociedade, mas busca sempre se expandir e se consolidar.

Mann (1984), ao descrever o que batizou de poder instraestrutural (insfrastructural power) do Estado, enxerga relações entre seu poder e a sua capacidade de penetrar na sociedade para executar decisões de forma legítima ao longo de seu território, decisões estas que podem surgir na forma de políticas públicas. O poder infraestrutural do Estado se contrapõe ao poder despótico, no qual as decisões são implementadas à força, contra a vontade e a aceitação da sociedade e, portanto, de forma ilegítima. A ação legítima, no entanto, não é facilmente definida. 
Rocha (2005, p. 18) afirma que "uma política tem sucesso quando estimula grupos e alianças que defendam sua continuação e expansão". Legitimidade, nesse sentido, estaria vinculada à aceitação social da ação estatal. Isto é particularmente verdadeiro no caso desta política pública de caráter participativo, que conta com a colaboração da sociedade civil em diversos níveis e que será apresentada no capítulo a seguir. Portanto, é possível inferir que, para o autor, as políticas de sucesso exclusivamente devem surgir de Estados que as implementem utilizando seu poder insfraestrutural, como idealizado por Mann (1984). Esta perspectiva será fundamental para compreender o que será possível através da confecção de uma política pública adequada para a concretização de um direito humano. Se o objetivo de tais políticas é, por um lado, inserir gradualmente novos princípios e práticas, é possível que estas sejam utilizadas para direcionar a cultura de uma sociedade rumo à cidadania e ao respeito aos direitos humanos.

Para estudar a possibilidade de políticas públicas incentivarem a emergência de novos comportamentos nas sociedades em que são implementadas, este trabalho propõe um estudo de caso sobre o programa de patrocínio privado para reassentamento de refugiados promovido pelo governo do Canadá. Apesar de se tratar de uma demanda da sociedade civil, a política pública é construída no âmbito governamental e, a partir de então, a sociedade é convidada para participar da implementação desta nova política como parte fundamental e indispensável para o sucesso da mesma.

A elaboração de estudos sobre políticas públicas anteriores é importante para promover o que Peter A. Hall (1993) definiria como policy learning, ou aprendizado político. Para que os burocratas e agentes governamentais responsáveis pela elaboração e pela implementação de novas políticas públicas sejam capazes de construir roteiros de ação e programas mais preparados para lidar com os desafios propostos pelo contexto histórico, político e social que esttas buscam alterar, é necessário que antes compreendam não somente este contexto, mas também as políticas públicas que as antecederam. Segundo o autor (1993, p. 277), "os interesses e ideais que policymakers ${ }^{3}$ perseguem a qualquer período no tempo são moldados por 'legados políticos' ou 'reações significativas às políticas anteriores". Skocpol e Finegold (1982), em seu clássico estudo sobre as políticas que compuseram o New Deal, do presidente estadunidense Franklin Delano Roosevelt, corroboram a afirmação de Hall (1993), demonstrando que as burocracias que mais possuíam aprendizado político foram as mais capazes de implementar as novas políticas federais.

\footnotetext{
${ }^{3}$ Ou formuladores de políticas.
} 
O estudo sobre como o Estado enfrenta seus desafios internos e externos, como os fatores políticos e sociais interagem e afetam o jogo político e como políticas anteriores influenciam o processo político posterior é objeto de análise da vertente neoinstitucional dos estudos de política pública (Rocha, 2005). O último fenômeno é descrito por Skocpol (1995) como fundamental para o sucesso de uma nova política, principalmente através do efeito de feedback (Rocha, 2005). A existência de respostas ou reações por parte de grupos e organizações sociais às políticas públicas, o feedback, é, portanto, importante para os idealizadores de políticas públicas e para os atores políticos - o sucesso ou fracasso de uma política é visto por Hall (1993) como aprendizado social, orientando atores sobre os melhores rumos e estratégias para eventuais decisões futuras. O autor afirma que "os interesses e ideais que policymakers perseguem a qualquer período no tempo são moldados por 'legados políticos' ou 'reações significativas às políticas anteriores' (p. 277).

Seguindo tais prerrogativas, este artigo tem o objetivo de estudar a viabilidade do uso de políticas públicas para implementar princípios relacionados aos direitos humanos, através de um estudo de caráter dedutivo. Como caso a ser estudado, avaliar-se-á a política para refugiados canadense, considerada uma das mais progressistas na atualidade. As discussões propostas por este artigo abordam a relação desta política pública com o Direito Internacional dos Refugiados, um dos regimes de direitos humanos mais reconhecidas na contemporaneidade, que inicia sua construção formal após a Segunda Guerra Mundial, no âmbito da recém-criada Organização das Nações Unidas (ONU) - anteriormente, crises migratórias eram resolvidas, em sua grande maioria, através de medidas ad hoc (Jubilut, 2007).

O grande número de pessoas forçadas ao deslocamento em fuga da guerra configurou uma das maiores catástrofes humanitárias registradas. Perante este desafio, a ONU instaurou o Alto Comissariado das Nações Unidas para Refugiados (ACNUR), que se tornaria o principal organismo sobre refugiados e outros migrantes humanitários dentro da organização internacional (Jubilut, 2007; Ramos, 2011). A criação do ACNUR possibilitou a criação da Convenção de 1951 Relativa ao Estatuto dos Refugiados, que, ao lado do Protocolo de 1967 Relativo ao Estatuto dos Refugiados, configuram os dois principais documentos do Direito Internacional dos Refugiados.

A Convenção de consagraria o reconhecimento do status de refúgio a pessoas com um bem fundado temor de perseguição em virtude de sua raça, religião, nacionalidade, grupo social ou opiniões politicas, além de proibir o retorno compulsório destes migrantes em condições que colocassem suas vidassem perigo (non refoulement) (Jubilut, 2007; Ramos, 2011). Todavia, para a Convenção de 51, apenas os europeus afetados pela Segunda Guerra Mundial poderiam solicitar a proteção internacional do Estatuto do Refúgio, estabelecendo reservas temporal e geográfica 
que só seriam revistas com o Procotolo de 1967, que efetivamente as extinguiu e expandiu o Direito Internacional dos Refugiados à todos aqueles que sofressem perseguição estatal pelos motivos contemplados na Convenção, independente de seu país de origem. Todavia, frente aos diferentes perfis de migração humanitária, o regime não contempla grande parte dos migrantes forçados (Betts, 2010).

Este artigo divide-se em três outras seções, além desta introdução: a primeira, com o intuito de apresentar e descrever a política pública do Canadá referente ao reassentamento de refugiados, com enfoque em uma inovação adotada pelo país, o reassentamento por patrocínio privado; a segunda, de caráter crítico, analisará as implicações da política canadense, incluindo impactos que já podem ser percebidos e observações sobre possíveis déficits ou características positivas sobre a estrutura desta instituição; por fim, a seção final consiste nas conclusões encontradas durante este estudo.

\section{O PATROCÍNIO PRIVADO NO CANADÁ}

No Canadá, as migrações fazem parte da história do país e seu envolvimento na recepção de indivíduos fugindo de crises econômicas, guerras, fome e perseguições teve início antes da criação dos principais instrumentos jurídicos internacionais voltados ao refúgio. Entretanto, a possibilidade de que estes indivíduos tivessem sido vítimas perseguições ou violações humanitárias não esteve entre as principais preocupações do governo durante muitos anos. Isto é, tendo em vista que até meados dos anos 1970 o país não possuía políticas especialmente orientadas para a admissão de refugiados e só veio a aderir a Convenção de Genebra de 1951 e seu Protocolo de 1967 no ano de 1969, tem-se que, anteriormente a esse período, os refugiados eram acolhidos como parte do esquema geral de imigrantes, desenvolvido para promover os interesses econômicos do país (Hathaway, 1988).

Diferentemente de nações mais antigas, com bases populacionais
estabelecidas, o Canadá precisava promover a imigração como um meio de
preencher os espaços de um grande país em desenvolvimento e assegurar a
energia e talento necessários para aproveitar seus ricos recursos naturais.
Imigrantes motivados e hábeis, tanto refugiados como migrantes
econômicos, eram bem-vindos, sendo-lhes proporcionados direitos e
benefícios, incluindo acesso à cidadania canadense (HATHAWAY, 1998, p.
679 , tradução nossa) ${ }^{4}$.

Com o fim da Segunda Guerra Mundial, o mundo presenciou um número de migrantes forçados buscando proteção fora de seus países até então nunca visto na

\footnotetext{
${ }^{4}$ No original, de língua inglesa: "Unlike many older nations with established population bases, Canada needed to promote immigration as a means of filling the spaces of a large and developing country, and of securing the energy and talent requisite to the harnessing of its rich natural resources. 4 Motivated and skilled immigrants, whether refugees or economic migrants, were welcomed and afforded a full array of rights and benefits, including access to Canadian citizenship".
} 
história, o que culminou na Convenção das Nações Unidas de 1951 e seu subsequente Protocolo, em 1967. Tendo em vista que a Convenção proibia o retorno compulsório de refugiados em condições que colocassem suas vidas em perigo (o princípio do non refoulement), a ratificação do documento era percebida como problemática pelo Canadá, já que o acolhimento de refugiados estaria mais longe de seu escopo discricionário (Hathaway, 1988). Além disso, no contexto da Guerra Fria, alianças ideológicas moldariam a política migratória do Canadá, o que teria incentivado o reassentamento de 40.000 refugiados da Hungria ${ }^{5}$ em 1956 e 12.000 vindos da Checoslováquia ${ }^{6}$ de 1968 a 1969, como uma forma de deslegitimar estes governos (EPP, 2017). Como exposto por Epp, políticos citariam a impossibilidade de deportar simpatizantes ao comunismo como uma das razões para não ratificar os documentos internacionais.

Para Epp (2017), a sociedade civil teria tido um papel de extrema importância ao longo do século XX, tendo advogado e agido de forma intensa para garantir uma melhor resposta para os migrantes forçados no Canadá. E contornar os limites impostos pelo governo nesse âmbito ao longo do século XX. Labman (2016) nota o surgimento do Jewish Immigration Aid Services (JIAS) e do Mennonite Central Committee no imediato pós-Primeira Guerra Mundial como duas importantes iniciativas para auxiliar a migração de alguns grupos. No período posterior a Segunda Guerra Mundial, outras iniciativas como o Canadian Christian Council for the Resettlement of Refugees (1946), o Approved Church Program (1953) eoNational Inter-Faith Immigration Committee (1968) teriam surgido para acolher e prover suporte a um número superior de refugiados.

Assim, em convergência com os anseios da sociedade civil canadense por uma resposta mais humanitária em relação aos refugiados, o país ratificou a Convenção de 1951 e seu Protocolo de 1967 no final dos anos 1960, tornando necessária uma revisão em sua legislação de migrações e colocando fim a uma série de ações ad hoc. Em 1973, o governo teria anunciado seus planos para criar uma nova lei de migrações, sendo esta uma oportunidade para que grupos religiosos pedissem pela formalização do patrocínio privado, que já vinha ocorrendo de forma informal (Hathaway, 1988; Labman, 2016; EPP, 2017).

A aprovação do Immigration Act em 1976 criaria, pela primeira vez, a distinção entre refugiados e outros imigrantes na legislação canadense (EPP, 2017). Além prever o acolhimento de refugiados pelos motivos previstos na Convenção de 1951, a lei também previa o acolhimento de indivíduos em situações similares ao refúgio que não

\footnotetext{
5 Entre 1949 e 1989 o país foi intitulado como República Popular da Hungria e seu principal partido, o Partido Socialista dos Trabalhadores Húngaros, operava sob influência da União Soviética (Borhi, 2014).

${ }^{6}$ Entre 1960 e 1989 o país foi intitulado como República Socialista da Tchecoslováquia e seu Principal partido, o Partido Comunista da Checoslováquia, operava sob influência da União Soviética (Mcdermott, 2015).
} 
envolvessem perseguições, como indivíduosseriamente afetados por conflitos civis ou armados, ou que tivessem tido seus direitos humanos básicos violados - algo presente na legislação do país até os dias de atuais. O Immigration Act de 1976 também acabaria por institucionalizar o patrocínio privado, que teve início em 1979. Como resultado imediato, a população do Canadá foi responsável por patrocinar 34.000 dos 60.000 refugiados acolhidos vindos do Camboja, Laos e Vietnã entre 1979 e 1980, tendo recebido a Medalha Nansen do ACNUR em reconhecimento de sua ação no ano de 1986 (CCR, 2018).

Aprovado em 2001, o Immigration and Refugee Protection Act substituiu o Immigration Act de 1976 e vigora desde 2002. No que tange os refugiados, as principais provisões da lei foram mantidas e, assim como antes, o sistema de proteção e acolhimento desses migrantes forçados pode ser dividido em dois: o Programa para Refugiados que solicitaram o refúgio no Canadá, e o Programa de Reassentamento para Refugiados e Migrantes Humanitários. O programa de reassentamento se divide em três principais esferas: (1) Government Assisted Refugees (GARs); (2) Private Sponsored Refugees (PSRs); (3) Blended Visa-Office Referred (BVOR). Também, partir da chegada ao país, todos os refugiados reassentados passam a ter status de residência permanente e podem solicitar cidadania após três anos de permanência (Canadá, 2018b, 2018c, 2018e).

Os GARs são refugiados reconhecidos pelos motivos da Convenção de 1951 e nomeados pelo ACNUR. Após a chegada ao Canadá, estes refugiados contam com o apoio de organizações autorizadas pelo governo - que devem prover itens básicos e um local temporário para moradia, até o refugiado encontrar um local permanente - e com um suporte financeiro provido pelo Estado, que pode durar até um ano (CANADÁ, 2014b). Segundo Simões et al. (2018), em 2015, na cidade de Toronto, a quantia mensal era de 781 dólares canadenses (CAD) por indivíduo.

Os PSRs podem ser refugiados reconhecidos pelos motivos da Convenção de 1951 e refugiados afetados por outras questões humanitárias. Isto é, essa categoria do programa de reassentamento canadense também abarca indivíduos que foram seriamente afetados por guerras civis, conflitos armados, ou que tenham sido continuamente privados de seus direitos humanos básicos. O processo de determinação de status seria feito individualmente, por um oficial canadense (Estados Unidos, 2016). Diferentemente de como acontece com os GARs, estes refugiados são nomeados e auxiliados de forma prática e financeira por atores privados por um período de até um ano, que pode se estender até três anos em circunstâncias excepcionais. Dentre as responsabilidades dos patrocinadores privados, podem ser citadas: prover moradia, alimentação, vestimentas, custos relativos ao transporte local e impostos, bem como auxílio social e prático, como através da facilitação do acesso a 
emprego (ou escola, no caso de crianças e adolescentes), a aulas de inglês ou francês, serviços médicos e odontológicos, serviços bancários, grupos de suporte da comunidade ou outras orientações gerais acerca da vida no Canadá (Canadá, 2016a). Cabe ressaltar que o programa patrocínio privado é visto como uma iniciativa complementar aos compromissos do governo para os GAR's, não sendo um programa substituto e possibilitando que "cidadãos canadenses e residentes permanentes sejam aptos a dar oportunidades adicionais para refugiados vivendo no exterior [...]" (Canadá, 2016e, p.5, tradução nossa) ${ }^{7}$.Logo, segundo o Canadian Council for Refugees ${ }^{8}(C C R)$ :

\begin{abstract}
Todo ano, o governo se compromete, em nome dos canadenses, a reassentar um determinado número de refugiados. Tudo que os canadenses fazem através do patrocínio privado está para além desse compromisso. Isso significa que [o patrocínio privado] possibilita que os canadenses ofereçam proteção e um lar permanente para um número extra de refugiados, que, em outras circunstâncias, não teriam oportunidade (CCR, 2013, p. 1, tradução nossa) $)^{9}$.
\end{abstract}

Cidadãos e residentes canadenses estão aptos a se tornarem patrocinadores por meio de: (1) Sponsorship Agreement Holders (SAHs), (2) Community Sponsors, ou (3) Groups of Five (RSTP, 2018). A categoria SAH se refere a organizações com personalidade jurídica, já os Community Sponsors podem ser organizações, corporações ou associações. Organizações registradas como SAHs podem autorizar outros grupos (denominados Constituent Groups) a se tornarem patrocinadores sob a égide se seu próprio registro e atuar como intermediárias institucionais entre os patrocinadores e o governo (Macklin et al., 2018). Os Groups of Five são formados por cinco cidadãos ou residentes permanentes, existindo a possibilidade da realização de parcerias com outros indivíduos ou grupos autorizados pelo governo.Além de demonstrar capacidade de prover auxílio prático, um dos critérios para se tornar patrocinador é a demonstração da capacidade financeira de arcar coma totalidade dos custos $^{10}$ do reassentamento, estimados em $\$ 13.500$ CAD para uma família de uma pessoa e $\$ 33.700$ CAD para uma de seis membros (Canadá, 2018f).

Desde 2013, o Canadá também promove o BVOR, onde o governo, patrocinadores privados e o ACNUR atuam de forma conjunta. Através desta divisão do programa, são reassentados refugiados nomeados pelo ACNUR que se enquadrem nos motivos de perseguição da Convenção de 1951. Nesta via, os refugiados contam com o mesmo

\footnotetext{
${ }^{7}$ No original, de língua inglesa: "Canadian citizens and permanent residents are able to provide additional opportunities for refugees living abroad".

${ }^{8}$ O CCR é uma ONG e trabalha de forma conjunta com o governo e a população canadense (2018)

${ }^{9}$ No original, de língua inglesa: "each year the government makes its commitment, on behalf of Canadians, to resettle a certain number of refugees. Anything that Canadians do through private sponsorship is on top of that commitment. This means that it allows Canadians to offer protection and a permanent home to extra refugees, who would not otherwise have the opportunity".

${ }^{10}$ Os custos podem variar de acordo com a cidade onde o refugiado é reassentado (ibidem).
} 
auxílio prático e social oferecido pelos atores privados que os PSRs, porém, o governo canadense é responsável por prover os seis primeiros meses de auxílio financeiro e os patrocinadores são encarregados de prover os seis últimos (Canadá, 2016c). A tabela 1, a seguir, sintetiza as características de todas as divisões do programa de reassentamento canadense.

\begin{tabular}{|c|c|c|c|}
\hline & GAR & PSR & BVOR \\
\hline Nomeação & $\begin{array}{l}\text { ACNUR ou outras } \\
\text { organizações } \\
\text { designadas }\end{array}$ & Atores privados & $\begin{array}{l}\text { ACNUR ou outras } \\
\text { organizações } \\
\text { designadas }\end{array}$ \\
\hline $\begin{array}{l}\text { Classes de } \\
\text { refugiados }\end{array}$ & $\begin{array}{l}\text { Refugiados de acordo } \\
\text { com a Convenção de } \\
1951\end{array}$ & $\begin{array}{l}\text { Refugiados de acordo } \\
\text { com a Convenção de } \\
1951 \text { e refugiados } \\
\text { vítimas de outras } \\
\text { violações } \\
\text { humanitárias }\end{array}$ & $\begin{array}{l}\text { Refugiados de acordo } \\
\text { com a Convenção de } \\
1951\end{array}$ \\
\hline $\begin{array}{l}\text { Auxílio } \\
\text { financeiro }\end{array}$ & Governo canadense & $\begin{array}{l}\text { Patrocinadores } \\
\text { privados }\end{array}$ & $\begin{array}{l}\text { Governo canadense e } \\
\text { patrocinadores } \\
\text { privados }\end{array}$ \\
\hline $\begin{array}{l}\text { Auxílio } \\
\text { prático } \\
\text { social }\end{array}$ & Governo canadense & $\begin{array}{l}\text { Patrocinadores } \\
\text { privados }\end{array}$ & $\begin{array}{l}\text { Patrocinadores } \\
\text { privados }\end{array}$ \\
\hline
\end{tabular}

Tabela 1: Divisões e características do programa de reassentamento canadense. Fontes: Canadá 2014b, 2016a, 2016e, 2018c, 2018d, 2018e

\section{AS CONSEQUÊNCIAS PRÁTICAS DO PROGRAMA}

Apesar de não estar entre os países que mais acolhem refugiados no mundo, o Canadá ocupa um lugar de proeminência no reassentamento destes migrantes. Historicamente, o país tem estado entre as três nações que mais reassentam refugiados no globo, tendo, desde 2014, ficado apenas atrás dos EUA. Entretanto, uma análise per capita colocaria o Canadá em uma posição superior. Isto é, em 2017, o país teria reassentado 725 refugiados por milhão de habitantes, enquanto, nos EUA, a mesma proporção seria de 102 refugiados por milhão de habitantes (PEW RESEARCH CENTER, 2018). 


\begin{tabular}{|l|l|l|l|}
\hline \multicolumn{1}{|c|}{ Ano } & \multicolumn{1}{|c|}{ GARs } & \multicolumn{1}{|c|}{ PSRs } & \multicolumn{1}{c|}{$\begin{array}{c}\text { Proporção de PSRs no total de } \\
\text { reassentamentos }\end{array}$} \\
\hline 2008 & 7925 & 3512 & $32,5 \%$ \\
\hline 2009 & 7425 & 5036 & $40,4 \%$ \\
\hline 2010 & 7264 & 4833 & $40,3 \%$ \\
\hline 2011 & 7363 & 5584 & $43,1 \%$ \\
\hline 2012 & 5412 & 4225 & $45,1 \%$ \\
\hline 2013 & 5661 & 6269 & $51,4 \%$ \\
\hline 2014 & 7573 & 4560 & $37,1 \%$ \\
\hline 2015 & 9448 & 9747 & $47,3 \%$ \\
\hline 2016 & 23624 & 18645 & $40,0 \%$ \\
\hline 2017 & 8823 & 16873 & $62,6 \%$ \\
\hline
\end{tabular}

Tabela 2: Dados consolidados sobre reassentamento no Canadá (2008-2014). Fontes: Canadá, 2016b, 2018a; OECD, 2016

Ainda que no período de 2008 a 2012 o número de PSRs tenha sido inferior àquele de GARs e ter representado cerca de $32,1 \%$ a $45,1 \%$ de todos os esforços do país no reassentamento, no ano de 2013, o número de PSRs foi maior que o de refugiados reassentados pelo governo (tabela 1). Inclusive, em 2017, segundo as metas do governo, o número de PSRs (16 mil) foi maior que o dobro de GARs (7.5 mil) (tabela 2). Segundo o país, o aumento da proporção de PSRs teria ocorrido por conta de um "[...] crescimento significativo no numero de canadenses que se inscreveram para patrocinar refugiados" (Canadá, 2016c, S/P, tradução nossa) ${ }^{11}$.

É interessante observar que, assim como apresentado na Tabela 2, esse aumento na parcela representada pelos PSRs no total de reassentamentos está, inclusive, proposto nas metas do governo canadense. Outra preocupação emerge a partir de então: até que ponto realmente há intenção de manter o patrocínio privado como uma ferramenta complementar para os esforços do Estado se, de fato, o aumento de refugiados admitidos como GAR não acompanha o aumento daqueles admitidos como PSR? O caráter de adicionalidade da política pública parece admitir que, independente dos reassentamentos por via privada, o Estado não fica isento de, também, agir em prol ${ }^{11}$ No original, de língua inglesa: "[...] significant growth in the number of Canadians who have applied to sponsor
refugees". 
daqueles que busquem refúgio no Canadá, mas, apesar disso, parece admitir-se uma menor participação estatal neste processo.

\begin{tabular}{|l|l|l|l|l|}
\hline \multicolumn{1}{|c|}{ Ano } & \multicolumn{1}{|c|}{ GAR } & \multicolumn{1}{|c|}{ PSR } & \multicolumn{1}{|c|}{ BVOR } & $\begin{array}{l}\text { Proporção de PSRs no total } \\
\text { de reassentamentos }\end{array}$ \\
\hline 2012 & 7800 & 5500 & 0 & $41,3 \%$ \\
\hline 2013 & 7100 & 6300 & 200 & $46,3 \%$ \\
\hline 2014 & 7100 & 6300 & 500 & $45,3 \%$ \\
\hline $2015^{12}$ & 5800 & 4500 & 700 & $40,9 \%$ \\
\hline 2016 & 24600 & 17800 & 2400 & $40,3 \%$ \\
\hline 2017 & 7500 & 16000 & 1500 & $64,0 \%$ \\
\hline 2018 & 7500 & 18000 & 1500 & $66,7 \%$ \\
\hline 2019 & 8500 & 19000 & 1650 & $65,2 \%$ \\
\hline 2020 & 10000 & 20000 & 1700 & $63,1 \%$ \\
\hline
\end{tabular}

Tabela 3: Metas para o programa de reassentamento canadense (2012-2020). Fontes: Canadá, 2011,

2012, 2013, 2014a, 2015, 2016d, 2017

Além de projetado para ser complementar aos esforços do governo para os GARs, tem-se que o patrocínio privado também seria complementar no sentido de auxiliar o processo de integração local dos refugiados, trabalhando a favor da construção de mais laços entre o refugiado e a sociedade acolhedora, o que thes garantiria melhores condições de vida e trabalho. Isto é, por vezes, e, especialmente durante o primeiro período posterior a chegada ao país de acolhimento, os principais contatos que um refugiado tem com a população receptora são através de oficiais do governo e provedores de serviços, o que resultaria em pouco contato com a sociedade que o acolhe (Kumin, 2015). Assim, tendo em vista que a integração local é amplamente reconhecida como um processo de 'mão dupla', envolvendo ajustes pelas sociedades acolhedoras e pelos recém-chegados, o patrocínio privado poderia ajudar a encurtar o gap cognitivo entre os refugiados e as comunidades receptoras. Dessa forma, através da construção de mais laços com a sociedade e de um contato frequente com seus patrocinadores, os refugiados reassentados pelo patrocínio privado também teriam acesso a melhores condições econômicas quando comparados aos refugiados reassentados governo. ${ }^{12}$ No ano de 2015 , foram utilizados os números referentes aos níveis mínimos de refugiados a serem reassentados
pois não há informações sobre a meta referente àquele ano. 
Em 2016, uma pesquisa o governo canadense apontava que os PSRs tendiam a ter mais acesso a trabalho, maior renda, e menor dependência de programas de suporte de renda, se incluindo economicamente de forma mais rápida que os GARs. Focando nas famílias reassentadas em 2002, a pesquisa revelava que, em seu primeiro ano no Canadá, 50\% dos PSRs encontraram um emprego, enquanto apenas $12 \%$ dos GARs tinham conseguido o mesmo. Entretanto, após cinco anos, 58\% dos GARS e 69\% dos PSRs teriam obtido acesso ao trabalho. Algo similar aconteceria com os níveis de renda, que tenderiam a ser menores entre os GARs nos primeiros anos de admissão no Canadá, porém, se elevariam para um nível próximo àquele dos PSRs depois dos primeiros cinco anos no país (Kumin, 2015; Canadá, 2016c).

Gráfico 1: Porcentagem de famílias de refugiados que declararam ter renda laboral por anos de admissão e categoria de reassentamento ${ }^{13}$

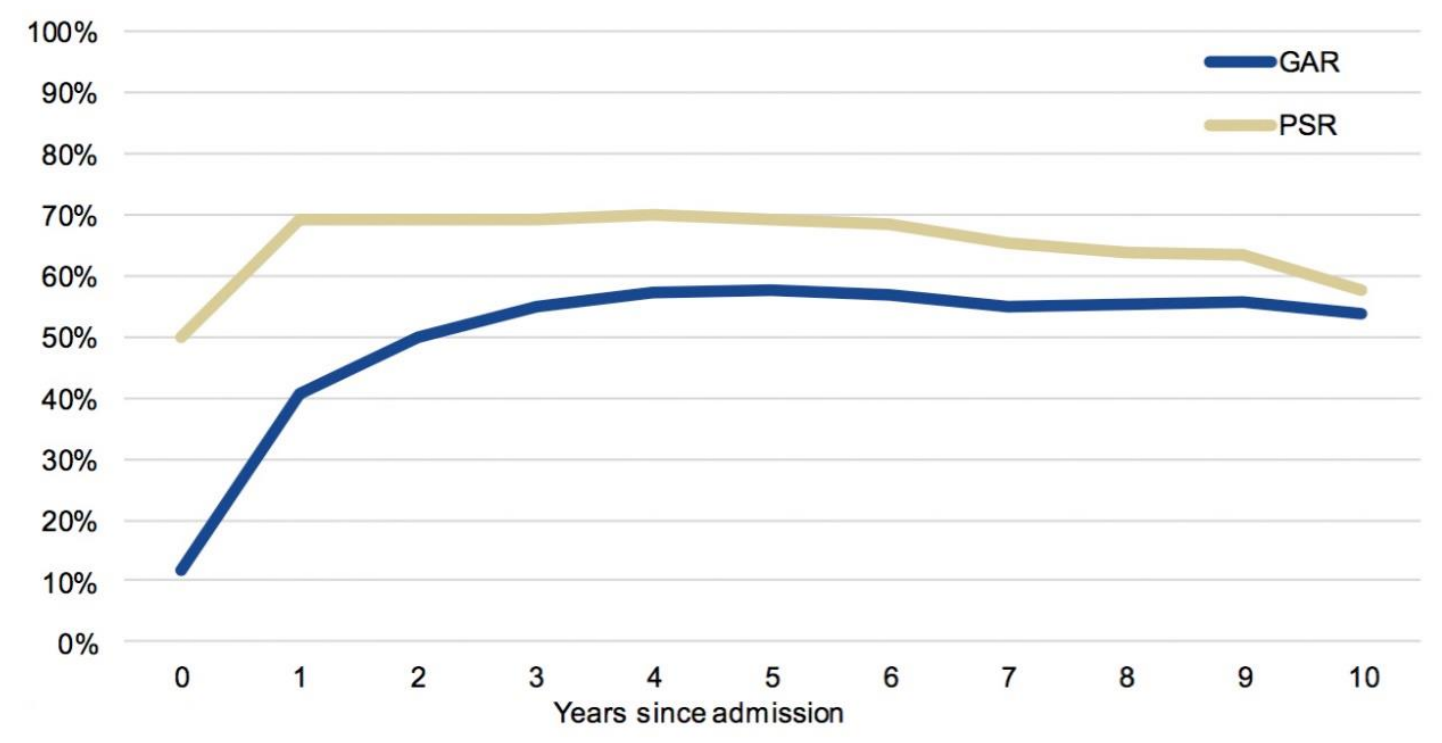

Fonte: Extraído de: Canadá, 2016a

A transição do status de residência permanente para cidadania e consequente aquisição de direitos políticos também é de grande relevância para a integração local dos refugiados, podendo ocorrer tanto para os refugiados de todas as vidas do programa de reassentamento. Isto é, através de mecanismos como o voto, estes migrantes podem ter suas demandas ouvidas e atendidas, bem como se tornar capazes de influir sobre o rumo de suas próprias vidas e ter um papel um papel mais ativo na sociedade. Apesar de não imediata, a transição do status de residência permanente

${ }^{13} \mathrm{~A}$ reta horizontal "years since admission"representa os anos decorridos desde que a família foi reassentada no Canadá. 
para cidadania ainda ocorre de maneiro mais rápida no Canadá que em outros países, como o Brasil, onde o mesmo processo levaria, no mínimo, quinze anos (Moreira, 2014; Brasil, 2018).

Ainda, tem-se que outra questão central de qualquer programa de reassentamento é como selecionar os refugiados a serem acolhidos. Em programas liderados pelo Estado, a seleção é usualmente feita pelo ACNUR, através critérios de vulnerabilidade ou através de critérios particulares do país, baseados nos interesses nacionais. Entretanto, tendo em vista que o programa de patrocínio privado permite que o patrocinador nomeie qual refugiado ele deseja reassentar, tem-se que, por vezes, motivos ou conexões pessoais podem incentivar seu engajamento. Segundo Brian Dick, membro da Associação de Sponsorship Agreement Holders ${ }^{14}$, dentre as principais motivações dos patrocinadores, constariam: conexões com familiares ou amigos em necessidade de reassentamento, afinidade com certos grupos (como refugiados LGBTI), motivações religiosas, comprometimento com a causa - inclusive por parte de refugiados que foram reassentados no passado - e o sentimento, entre muitos canadenses, de que patrocinar refugiados se tornou uma parte importante da identidade nacional (OECD, 2016; Refugee Council Of Australia, 2017).

Apontando para aquilo que seria o risco de organizações de caráter étnico, religioso e político focarem apenas em determinadas categorias de pessoas - o que levaria a exclusão de outras, inclusive as mais vulneráveis -, a Organização para a Cooperação e Desenvolvimento Económico (OECD) recomenda que alguns dos lugares em programas de patrocínio privado sejam estabelecidos por critérios externos, como aqueles do ACNUR ou do Estado acolhedor (OECD, 2016). No Canadá, isto teria sido concretizado através do BVOR, o programa misto entre a sociedade civil e o governo, no qual os refugiados são nomeados pelo ACNUR. Assim, segundo o governo canadense, uma maior rapidez no processo desta divisão do programa ${ }^{15}$ de reassentamento e 0 esgotamento das oportunidades de patrocinar um PSR - vale lembrar que, todo ano, o país define quantidades máximas de PSRs a serem reassentados -, levariam os patrocinadores a se engajar no programa misto (Canadá, 2018). Entretanto, desde seu lançamento, em 2013, o BVOR foi responsável por acolher um número menor de refugiados quando comparado às outras divisões do programa de reassentamento.

\section{CONCLUSÕES}

A partir do caso do programa de reassentamento de refugiados, podemos observar que as mudanças propostas pelo governo canadense através da inserção desta

\footnotetext{
${ }^{14}$ Os Sponsorship Agreement Holders são um dos grupos aptos a patrocinar refugiados no Canadá (Canadá, 2016e). 15 Nesta via, os refugiados são previamente selecionados pelo ACNUR, tornando o prazo de deslocamento até o país mais rápido que aquele dos PSRs e GARs, visto que eles tendem a já estarem prontos para a viagem (Canadá, 2018e).
} 
nova instituição, desta nova política pública foi possível transformar as demandas sociais, a percepção deste problema público, em uma nova cultura para a sociedade canadense.

O Canadá, além de ser o país que mais acolhe refugiados no mundo em comparação à sua população, reassentando cerca de 725 refugiados para cada milhão de habitantes, tornou-se um forte empreendedor dos direitos dos refugiados na comunidade internacional. Além disso, como apresentado na Tabela 1, os dados consolidados apresentam que houve adesão da sociedade civil ao programa de reassentamento privado, ultrapassando 40\% entre 2009 e 2012 e chegando a um ápice de $51,4 \%$ em 2013.

As projeções futuras apresentadas pela Tabela 2 sinalizam manutenção desta prática, admitindo cada vez mais a participação não-estatal neste processo. Por um lado, isto representa o sucesso da nova política pública em inspirar uma nova cultura assim como proposto por Rocha (2005). No entanto, deve-se atentar para a possibilidade de eximir o Estado de suas responsabilidades para este grupo vulnerável assim como proposto pelo princípio da adicionalidade, o papel do programa de reassentamento privado deve ser complementar aos esforços do Estado, não substituílo.

Outros problemas são apresentados pela estrutura do programa de PSR que mostram que, apesar de representar um progresso para aqueles em situação de vulnerabilidade, alguns alertas são necessários. Um detalhe importante a destacar é, sem dúvidas, a possibilidade de o patrocinador nomear o refugiado que deseja representar, o que pode possibilitá-lo a selecionar aquele ou aqueles que deseja acolher por motivos ou conexões pessoais, como identificação social ou pertencimento a grupo similar. Todavia, é possível que este caráter seletivo leve à exclusão daqueles que se encontram expostos a situações ainda mais graves. Como a OECD (2016) aponta, o ideal seria que fossem estabelecidos critérios externos, como acontece no BVOR.

Por outro lado, o reassentamento por via privada parece facilitar o processo de integração local dos refugiados, possibilitando que obtenham empregos e melhorem suas rendas e condições de vida em um período de tempo mais curto, o que é, sem dúvida, um progresso valioso. Ainda, a política para refugiados do Canadá possibilita que, independente do programa em que tenham tido seu status de pessoa vulnerável reconhecido, seja possível obter direitos políticos em um período relativamente curto e sem grandes impedimentos.

Conclui-se, assim, que, apesar dos déficits existentes e anseios sobre a política de reassentamento privado do Canadá, é indispensável apontar a importância que essa inovação institucional tem no processo de integração local e de proteção dos 
refugiados. Ainda, esta mudança institucional refletiu em modificações de comportamento na sociedade, demonstrando o sucesso da concretização de princípios de direitos humanos através de políticas públicas com desenho institucional adequado.

É possível inferir que a política de reassentamento canadense obteve sucesso, como definido por Rocha (2005), sendo capaz de inspirar grupos e indivíduos a proteger sua continuidade. O argumento de Bucci (2001) sobre a importância das políticas públicas para a concretização dos direitos humanos no âmbito interno dos Estados, como parte do Direito doméstico, gerando obrigações e a possibilidade de cobrança pelos indivíduos, parece ser corroborada pela política para refugiados do Canadá. Ao incorporar as normativas sobre refúgio e reassentamento no Direito canadense e, ainda, expandi-las, tornando o país um empreendedor dos direitos dos refugiados, é possível observar o poder transformativo desta nova política.

Portanto, este trabalho conclui que as políticas públicas configuram instrumentos apropriados, capazes de transformar direitos humanos, princípios com pouco ou nenhum poder jurídico, em recursos com poder legal, capazes de gerar obrigações jurídicas, possibilitando que indivíduos e grupos sociais reivindiquem sua proteção e garantia. Na busca pela proteção legal dos seres humanos descrita por Trindade (2003), parece razoável argumentar que, por mais que o reconhecimento internacional dos direitos humanos seja importante, é necessária, de forma simultânea, a ação estatal através de políticas públicas.

\section{REFERÊNCIAS BIBLIOGRÁFICAS}

Betts, A. (2010). 'Survival Migration: A New Protection Framework'. Global Governance, n. 16 , pp. 361-382.

Bielefeldt, H. (2006). 'Access to Water, Justice and Human Rights'; in: Riedel, E. H.; Rother, P. The Human Right to Water, Berlim: BWV Verlag, pp. 49-63.

Brasil (2018). Naturalização (Online). 2018 (online). Disponível em: <http://www.pf.gov.br/servicos-pf/imigracao/naturalizacao>. [Acesso em: 15 set. 2018].

Bucci, M. P. D. (2001). 'Buscando um Conceito de Políticas Públicas para a Concretização dos Direitos Humanos'; in: Bucci, M. P. D.; Saule Junior, N.; Arzabe, P. H. M.; Frischeisen, L. C. F. Direitos humanos e políticas públicas, São Paulo, Pólis, pp. 5-16.

(2006). 'Conceito de política pública em direito'; in: Bucci, M. P. D. (Org.).

Políticas Públicas: reflexões sobre o conceito jurídico, São Paulo: Saraiva, pp. 1-50. 
Canadá (2018a). 2018 Annual Report to Parliament on Immigration (Online). Disponível em: <https://www.canada.ca/content/dam/ircc/migration/ircc/english/pdf/pub/annualreport-2018.pdf>. [Acesso em: 21 nov. 2018]

(2011). Achieved - Notice - Supplementary Information to the 2012 Immigration Levels Plan (Online). Disponível em: <https://www.canada.ca/en/immigration-refugeescitizenship/news/notices/supplementary-information-2012-immigration-levelsplan.html>. [Acesso em: 15 set. 2018]

(2012). Achieved - Notice - Supplementary Information to the 2013 Immigration Levels Plan (Online). Disponível em: <https://www.canada.ca/en/immigration-refugeescitizenship/news/notices/supplementary-information-2013-immigration-levelsplan.html>. [Acesso em: 15 set. 2018].

(2013). Achieved - Notice - Supplementary Information to the 2014 Immigration Levels Plan (Online). Disponível em: <https://www.canada.ca/en/immigration-refugeescitizenship/news/notices/supplementary-information-2014-immigration-levelsplan.html>. [Acesso em: 15 set. 2018].

(2014a). Achieved - Notice - Supplementary Information to the 2015 Immigration Llan (Online). Disponível em: $<$ https://www.canada.ca/en/immigration-refugees-citizenship/news/notices/noticesupplementary-information-2015-immigration-levels-plan.html>. [Acesso em: 15 set. 2018].

(2018b). Application for Canadian citizenship under subsection 5(1) - Adults 18 years of age and older (CIT 0002) (Online). Disponível em: $<$ https://www.canada.ca/en/immigration-refugeescitizenship/services/application/application-forms-guides/guide-0002-applicationcanadian-citizenship-under-subsection-5-1-adults-18-years-older.html>. [Acesso em: 14 set. 2018].

(2016a). Evaluation of the Resettlement Programs (GAR, PSR, BVOR and RAP) (Online). Disponível em: <http://publications.gc.ca/collections/collection_2016/ircc/Ci4156-2016-eng.pdf>. [Acesso em: 26 ago. 2018].

(2016b). Facts and Figures 2016 (Online). Disponível em:<http://www.cic.gc.ca/opendatadonneesouvertes/data/Facts_and_Figures_2016_PR_EN.pdf>. [Acesso em: 21 nov. 2018].

(2014b). Government-Assisted Refugee Resettlement in Canada (Online). Disponível em: 
<https://www.canada.ca/content/dam/ircc/migration/ircc/english/pdf/pub/gar_eng.pdf >. [Acesso em: 25 ago. 2018].

(2018c). How Canada's refugee system works (Online). Disponível em: $<$ https://www.canada.ca/en/immigration-refugeescitizenship/services/refugees/canada-role.html>. [Acesso em: 25 ago. 2018].

(2018d). "How is the Blended Visa Office-Referred Program different from the regular Private Sponsorship of Refugees Program?" (Online). Disponível em: $<$ http://www.cic.gc.ca/english/helpcentre/answer.asp?qnum=770\&top=11>. [Acesso em: 28 ago. 2018].

(2016c). Key Highlights 2017 Immigration Levels Plan (Online). Disponível em: <https://www.canada.ca/en/immigration-refugees-citizenship/news/2016/10/keyhighlights-2017-immigration-levels-plan.html>. [Acesso em: 15 set. 2018].

(2015). Notice - Supplementary Information 2016 Immigration Levels Plan (Online). Disponível em: <https://www.canada.ca/en/immigration-refugeescitizenship/news/notices/notice-supplementary-information-2016-immigration-levelsplan.html>. [Acesso em: 15 set. 2018].

(2016d). Notice - Supplementary Information 2017 Immigration Levels Plan (Online). Disponível em: <https://www.canada.ca/en/immigration-refugeescitizenship/news/notices/notice-supplementary-information-2017-immigration-levelsplan.html>. [Acesso em: 15 set. 2018].

(2017). Notice - Supplementary Information 2018-2020 Immigration Levels Plan. 2017 (online). Disponível em: <https://www.canada.ca/en/immigration-refugeescitizenship/news/notices/supplementary-immigration-levels-2018.html>. [Acesso em: 15 set. 2018].

(2016e). Private Sponsorship of Refugees Program. Ottawa: Resettlement Operations Centre in Ottawa Settlement Operations Centre.

(2018e). Resettlement from outside Canada (Online). Disponível em: <https://www.canada.ca/en/immigration-refugees-citizenship/services/refugees/helpoutside-canada.html>. [Acesso em: 24 ago. 2018].

(2018f). Settlement Plan and Financial Assessment (Online). Disponível em: $<$ https://www.canada.ca/content/dam/ircc/migration/ircc/english/pdf/kits/forms/imm5 373ae.pdf>. [Acesso em: 25 ago. 2018].

CCR (2018a). About the CCR (Online). Disponivel em: <http://ccrweb.ca/en/about-ccr>. [Acesso em: 26 ago. 2018]. 
(2013). Important changes in Canada's Private Sponsorship of Refugees Program (Online). Disponível em: <http://ccrweb.ca/sites/ccrweb.ca/files/psr-changes2013.pdf>. [Acesso em: 26 ago. 2018].

(2018b). The Resettlement of Indochinese Refugees in Canada: Looking Back

after Twenty (Online). Years Disponível em:
<http://ccrweb.ca/sites/ccrweb.ca/files/staticfiles/20thann.html>. [Acesso em: 24 ago. 2018].

Dye, T. R. (2013). Understanding Public Policy. Upper Saddle River: Pearson Education, Inc., 14aㅡ ed.

EPP, M. (2017). Refugees in Canada: A Brief History. Ottawa: Canadian Historical Association.

Estados Unidos (2016). Refugee Law and Policy: Canada (Online). Disponível em: <https://www.loc.gov/law/help/refugee-law/canada.php> [Acesso em 06 de out. de 2018].

Hall, P. A. (1993). Policy Paradigms, Social Learning, and the State: the Case of Economic Policymaking in Britain. Comparative Politics, 25(3), pp. 275-296.

Hathaway, J. C. (1988). Selective concern: an overview of refugee law in Canada. McGill Law Journal, 8(2), pp. 676-715.

Jubilut, L. L. (2007). O Direito Internacional dos Refugiados e sua Aplicação no Ordenamento Jurídico Brasileiro. São Paulo: Editora Método.

Kumin, J. (2015). Welcoming Engagement: How Private Sponsorship Can Strengthen Refugee Resettlement in the European Union. Bruxelas: Migration Policy Institute Europe.

Labman, S. (2016). "Private sponsorship: complementary or conflicting interests?". Refuge, 32(2), pp. 67-80.

Mann, M. (1984). The autonomous power of the state: its origins, mechanisms and results. European Journal of Sociology, 25(2), pp. 185-213.

Macklin, A.; Barber, K.; Goldring, L.; Hyndman, J.; Korteweg, A.; Labman, S.; Zyfi, J. (2018). 'A Preliminary Investigation into Private Refugee Sponsors'. Canadian Ethnic Studies, [S.I.], 50(2), pp. 35-57, ago.

Moreira, J. B. (2014). 'Refugiados no Brasil: Reflexões Acerca do Processo de Integração Local'. Rev. Interdiscip. Mobil. Hum., Ano XXII, n. 43, pp. 85-98. 
OECD (2016). International Migration Outlook 2016, Paris, OECD Publishing.

Pew Research Center (2018). For the first time, U.S. resettles fewer refugees than the rest of the world (Online). Disponivel em: <http://www.pewresearch.org/fact$\operatorname{tank} / 2018 / 07 / 05 /$ for-the-first-time-u-s-resettles-fewer-refugees-than-the-rest-of-theworld/>. [Acesso em: 15 set].

Ramos, A. C. (2011). Asilo e Refúgio: semelhanças, diferenças e perspectivas. In: Ramos, A. C.; Rodrigues, G.; Almeida, G. A. (Org.). 60 anos de ACNUR: Perspectivas de futuro. São Paulo: CLA Cultural Ltda.

Refugee Council of Australia (2017). Canada's Private Sponsorship of Refugees program: potential lessons for Australia (Online). Disponível em: <https://www.refugeecouncil.org.au/wp-content/uploads/2017/08/Canadian-PSRpaper-1708.pdf>. [Acesso em: 15 set. 2018].

Rocha, C. V. (2005). Neoinstitucionalismo como modelo de análise para as Políticas Públicas: algumas observações. Civitas, 5(1), pp. 11-28.

RSTP (2018). The Private Sponsorship of Refugees (PSR) Program (Online). Disponivel em: <http://www.rstp.ca/en/refugee-sponsorship/the-private-sponsorship-of-refugeesprogram/>. [Acesso em: 03 set. 2017].

Salisbury, R. H. (1995). The Analysis of Public Policy: A Search for Theories and Roles. In: Theodoulou, S. Z.; Cahn, M. A. (Org.). Public Policy: The Essential Readings. Upper Saddle River: Prentice Hall, pp. 34-37.

Secchi, L. (2014). Políticas Públicas: Conceitos, Esquemas de Análise, Casos Práticos. São Paulo: Cengage Learning, 2a ed..

Skocpol, T. (1985). Bringing the State Back In. In: Strategies of Analysis in Current Research. In: Evans, P.; Rueschemeyer, D.; Skocpol, T.. Bringing the State Back In. Cambridge University Press, 1a ed, pp. 169-191.

.; Finegold, K., 1982. State Capacity and Economic Intervention in the Early New Deal. Political Science Quarterly, 97(2), pp. 255-278.

Simões, G.; Cavalcanti, L.; Araujo, D.; Brasil, E. (2018). 'Uma Aproximação ao Sistema Canadense de Reconhecimento da Condição de Refugiado'; in: Jubilut, L. L.; Frinhani, F. M. D.; Lopes, R. O. (Org.). Migrantes Forçad@s: Conceitos e Contextos. Boa Vista: Editora da Universidade Federal de Roraima, pp. 531-551.

Souza, C. (2006). Políticas Públicas: uma revisão de literatura. Sociologias, ano 8, n. 16, pp. 20-45. 
Theodoulou, S. Z. (1995). 'The Contemporary Language of Public Policy: A Starting Point'; In: Theodoulou, S. Z.; Cahn, M. A. (Org.). Public Policy: The Essential Readings. Upper Saddle River: Prentice Hall, pp. 1-9.

Trindade, A. A. C. (2003). 'Os Direitos Humanos e o Meio Ambiente'; in: Symonides, J. (Org.). Direitos Humanos: novas dimensões e desafios. Brasília: Edições Unesco Brasil, pp. 161-203. 